\title{
Walter Giger \\ The Division of Analytical Chemistry of the Swiss Chemical Society joins Analytical and Bioanalytical Chemistry as a supporting partner
}

Published online: 22 December 2004

(C) Springer-Verlag 2004

Starting in January 2005, the Division of Analytical Chemistry (DAC) of the Swiss Chemical Society becomes a supporting partner for the journal Analytical and Bioanalytical Chemistry. The Swiss community of analytical chemists is very proud that they can join this highly successful European journal.

The discipline of Analytical Chemistry has a long tradition in Switzerland. Swiss researchers have contributed substantially to the progress of this fascinating field of science. Gerold Schwarzenbach, Willy Simon and Kurt Grob could be named as representative examples of extraordinarily successful Swiss analytical chemists. If you look at the achievements of the recent Swiss Nobel laureates you can easily see that some of them-Heinrich Rohrer (scanning tunneling microscope, 1986), Richard R. Ernst (NMR, 1991) and Kurt Wüthrich (NMR, 2002) - can be thought of as analytical scientists.

At this point, I would like to make a plea for us to begin to move away from thinking in terms of "Analytical Chemistry", and move towards the more accurate term "Analytical Sciences". For many years now, analytical chemistry has encompassed work performed beyond its core boundaries: for example, studies that include various spectroscopic techniques, which are strictly speaking physical methods. More recent developments strongly emphasize biological methods. Such a transition is also clearly reflected in the title of this journal by the term "Bioanalytical". I support the notion that at the beginning of this century the scientific disciplines are opening up. On the other hand, we should not forget that much of what forms the basis of modern life sciences could in some sense be called analytical chemistry.
The Swiss Division of Analytical Chemistry (DAC) aims to establish a forum for analytical sciences and chemical measurement in chemistry, materials, environmental and life sciences. The goals of the DAC are to promote analytical science in all fields of science, to disseminate information, to create a forum that enables the discussion of topical issues and interdisciplinary collaboration, and to highlight the importance of analytical science in science and education, industry, commerce and government. If one looks at these objectives, it becomes very clear that it is a great opportunity for the Swiss DAC to join Analytical and Bioanalytical Chemistry, which is an excellent resource for the publication of new results and ideas. We are very much looking forward to a successful cooperation with the national societies, the publishers and the editors. We are strongly convinced that this will be a mutually profitable and satisfactory endeavour.

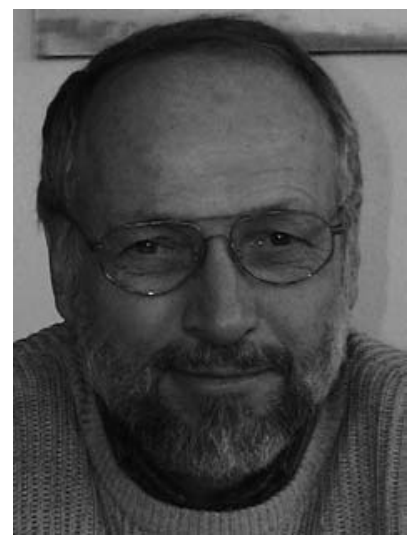

Walter Giger is currently the President of the DAC of the Swiss Chemical Society. He is heading the Division for Chemical Pollutants at the Swiss Federal Institute for Environmental Science and Technology (EAWAG) and is a professor at the Swiss Federal Institute of Technology (ETH) in Zurich. His current research interests are the development and application of trace analytical methods for emerging environmental contaminants, including endocrine disruptors, antibiotics, biocides and anticorrosives. 